TẠP CHÍ KHOA HỌC ĐẠI HỌC TÂN TRÀO

ISSN: $2354-1431$

http://tckh.daihoctantrao.edu.vn/

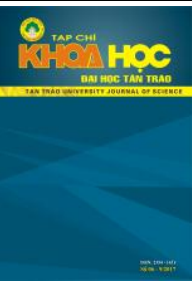

THE IN VITRO CYTOTOXICITY ACTIVITIES OF THE EXTRACTS FROM CALLICARPA MACROPHYLLA VAHL IN THAI NGUYEN PROVINCE

\author{
Vu Thi Thu Le ${ }^{l}$, Pham Thi Hong Minh ${ }^{2}$, Nguyen Thuong Tuan ${ }^{l}$, Dao Viet Hung ${ }^{l}$, Hoang Thi Bich ${ }^{2}$,Do Tien Lam ${ }^{2 *}$ \\ ${ }^{I}$ Thai Nguyen University of Agriculture and Forestry, Vietnam \\ ${ }^{2}$ Institute of Natural Products Chemistry, Vietnam \\ *Email address: dotienlam198@gmail.com \\ http://doi.org/10.51453/2354-1431/2021/553
}

\section{Article info}

Recieved:

30/3/2021

Accepted:

$3 / 5 / 2021$

\section{Keywords:}

Callicarpa macrophylla Vahl, Callicarpa, Lu-1, Hep-G2 and MCF-7.

\begin{abstract}
Callicarpa macrophylla Vahl. has widely been used in traditional medicine for the treatment such as gastrointestinal hemorrhage, coughing up blood, vomiting blood, nosebleeds, swollen and painful fall, rheumatism, bone pain, etc. The crude extract of the stem, leaves and fruits of Callicarpa macrophylla Vahl have exhibited demonstrated cytotoxicity against three human cancer cell lines (Lu-1, Hep-G2 và MCF-7) was tested by $\mathrm{SRB}$ assay with $\mathrm{CS}$ (\%) values ranging from $30,23 \pm 1,5$ to $90,22 \pm 0,15 \%$. Inside, The methanol extract of the leaves of Callicarpa macrophylla Vahl have showed relatively potent cytotoxicity with CS (\%) values ranging from $30,23 \pm 1,5$ to $47,84 \pm 2,1 \%$. The $n$-hexane fraction (L.CM.H) of the leaves of Callicarpa macrophylla Vahl have exhibited potent against three human cancer cell lines (Lu-1, Hep-G2 và MCF-7) than ethyl acetate fraction (L.CM.E) and methanol fraction (L.CM.M) with CS (\%) values ranging from $12,49 \pm 1,4$ to $20,18 \pm 0,8 \%$.
\end{abstract}


TẠP CHÍ KHOA HỌC ĐẠI HỌC TÂN TRÀO

ISSN: 2354 - 1431

http://tckh.daihoctantrao.edu.vn/

\title{
HOẠT TÍNH GÂY ĐỘC TẾ BÀO IN VITRO CỦA CÁC CẶN CHIẾT LOÀI TỬ CHÂU LÁ TO (CALLICARPA MACROPHYLLA VAHL.) Ở THÁI NGUYÊN
}

\author{
Vũ Thị Thu Lể ${ }^{l}$, Phạm Thị Hồng Minh ${ }^{2}$, Nguyễn Thuoong Tuấn ${ }^{l}$, Đào Việt Hùng ${ }^{l}$, Hoàng Thị Bích ${ }^{2}$, Đố Tiến Lâm ${ }^{2 *}$ \\ ${ }^{1}$ Truò̀ng Đại học Nông Lâm Thái Nguyên, Việt Nam \\ ${ }^{2}$ Viện Hóa học các Hơp chất thiên nhiên, Việt Nam \\ *Địa chi email: dotienlam198@ gmail.com \\ http://doi.org/10.51453/2354-1431/2021/553
}

\section{Thông tin bài viết}

Ngày nhận bài:

30/3/2021

Ngày duyệt đăng:

3/5/2021

\section{Tù̀ khóa:}

Callicarpa macrophylla

Vahl, Callicarpa, Lu-1,

Hep-G2 và MCF-7.

\section{Tóm tắt}

Cây Tử châu lá to (Callicarpa macrophylla Vahl) được sử dụng rộng rãi trong y học cổ truyền để chữa các bệnh như xuất huyết tiêu hóa, ho ra máu, nôn ra máu, chảy máu cam, đòn ngã sưng đau, thấp khớp, đau nhức xương... Cặn chiết tổng của thân, lá và quả của cây Tử châu lá to thể hiện hoạt tính gây độc in vitro trên ba dòng tế bào ung thư ở người (phổi: Lu-1, gan: Hep-G2 và vú: $\mathrm{MCF}-7)$ bằng phương pháp $\mathrm{SRB}$ với giá trị $\mathrm{CS}(\%)$ trong khoảng từ $30,23 \pm$ 1,5 đến $90,22 \pm 0,15 \%$. Trong đó, cặn chiết methanol tổng của lá cây Tử châu lá to (Callicarpa macrophylla $\mathrm{Vahl}$ ) thể hiện hoạt tính gây độc tế bào tốt với giá trị CS (\%) trong khoảng từ 30,23 $\pm 1,5$ đến 47,84 $\pm 2,1 \%$. Phân đoạn $n$ hexane (L.CM.H) của lá Tử châu lá to biểu hiện hoạt tính gây độc tế bào tốt hơn so với các phân đoạn ethyl acetate (L.CM.E) và methanol (L.CM.M) với giá trị CS $(\%)$ từ $12,49 \pm 1,4$ đến $20,18 \pm 0,8 \%$.

\section{MỞ ĐẦ}

Chi Callicarpa L. (Chi Tu hú, Nàng nàng hay Tử châu) có khoảng 140 loài, thuộc họ Verbenaceae, bao gồm các cây thân gỗ nhỏ và cây bụi, hay gặp phổ biến ở các vùng nhiệt đới và cận nhiệt đới, chủ yếu là ở các nước thuộc châu Á, một số loài cũng gặp ở vùng xích đạo châu Mỹ và Australia [2]. Ở Việt Nam, Theo tác giả Võ Văn Chi, chi Callicarpa có 14 loài [3,4], tác giả Phạm Hoàng Hộ thống kê chi Callicarpa có 26 loài [5], còn theo các nhà thực vật học thuộc Viện Sinh thái và tài nguyên sinh vật đã thống kê được 21 loài [6]. Được phân bố rải rác trong khắp cả nước ở Phía Bắc như Tuyên Quang, Lạng Sơn, Sơn La, Bắc Cạn, Phú Thọ, Bắc Giang, Ba Vì, Thái Nguyên, một số vùng miền trung như Nghệ An, Huế, Đà Nẵng, Khánh Hòa, Kon Tum, Đắc Lắc, Gia Lai, Ở phía Nam có Bình Dương, Đồng Nai [6].

Có nhiều loài cây thuộc chi Callicarpa được sử dụng trong y học dân gian nhiều dân tộc, ở các nước châu Á, Australia và Mỹ. Khoảng 20 loài thực vật chi Callicarpa được công bố về tác dụng và được sử dụng trong y học dân gian. Trong đó, một số loài biết đến hay được sử dụng trong y học cổ truyền của Trung Quốc và Nam Á trong việc điều trị bệnh viêm gan, bệnh thấp khớp, sốt, nhức đầu, khó tiêu và các bệnh khác. Một số loài Callicarpa đã được công bố được sử dụng chống lại ung thư 
(ví dụ, rễ cây Callicarpa americana để điều trị bệnh ung thư da và vỏ cây Callicarpa rubella để điều trị khối u của ruột già). Các dịch chiết thu được từ 14 loài trong chi Callicarpa đã được đánh giá tác dụng sinh học gồm khả năng kháng khuẩn, kháng nấm, chống côn trùng sinh trưởng, gây độc tế bào và các hoạt động phytotoxic. Ngoài các acid amin, benzenoid, carbohydrate đơn giản, lipid, diterpene, flavonoid, phenylpropanoid, phytosterol, sesquiterpene, và triterpene đã được phát hiện, phân lập từ chi Callicarpa [3].

Trong y học hiện đại, những kết quả nghiên cứu và thử nghiệm hoạt tính sinh học một số loài thực vật Callicarpa đã chứng minh rằng chúng chứa nhiều hoạt chất có tác dụng sinh học quý như hoạt tính kháng viêm, cầm máu, bảo vệ thần kinh, chống lao, giảm đau, kháng khuẩn, chống oxy hóa và chống ung thư... góp phần làm sáng tỏ việc sử dụng các thực vật chi này trong dân gian và cho thấy nó cung cấp một lượng lớn các chất chuyển hóa thứ cấp có hoạt tính sinh học [2,3].

Loài Callicarpa macrophylla Vahl ở Việt Nam, thuộc chi Callicarpa được nhân dân sử dụng thuốc chữa bệnh trong dân gian, có tiềm năng lớn về các hoạt chất sinh học mà trong nước vẫn chưa được nghiên cứu đầy đủ. Nghiên cứu này tập trung vào hoạt tính gây độc in vitro trên các dòng tế bào ung thư người: phổi (Lu-1), gan (Hep-G2) và vú (MCF7) của các cặn chiết thu được từ loài Callicarpa macrophylla Vahl theo phương pháp SRB.

\section{THỰC NGHIỆM}

\section{Nguyên liệu}

Lá, thân cành và quả loài Tử châu lá to thu tại huyện Đại Từ, tỉnh Thái Nguyên vào tháng 10 năm 2017 và được TS. Nguyễn Quốc Bình (Bảo tàng thiên nhiên Việt Nam - Viện Hàn lâm Khoa học và Công nghệ Việt Nam) xác định tên khoa học Callicarpa macrophylla Vahl, số tiêu bản CA20171002.HN lưu tại Bảo tàng Thiên nhiên Việt Nam.

\section{Phương pháp xử lý và chiết mẫu}

Các mẫu thực vật sau khi thu hái đều được xử lý theo phương pháp chung như sau:

Các mẫu thực vật sau khi thu hái được thái nhỏ, phơi trong bóng mát, sấy khô ở nhiệt độ $60^{\circ} \mathrm{C}$ đến khối lượng không đổi, sau đó đem nghiền nhỏ. Mẫu được ngâm chiết 3 lần methanol (ethanol) trong thiết bị siêu âm ở nhiệt độ phòng. Dịch tổng thu được cất kiệt dung môi dưới áp suất giảm, nhiệt độ $<50^{\circ} \mathrm{C}$ thu được cặn cô methanol (ethanol). Cặn cô methanol (ethanol) được thêm nước và chiết lần lượt với các dung môi có độ phân cực tăng dần $n$ hexane và ethyl acetate. Sau khi đuổi dung môi thu được cặn $n$-hexane, cặn ethyl acetate và cặn nước tương ứng.

\section{Phương pháp đánh giá hoạt tính gây độc tế bào in vitro theo phương pháp SRB}

\subsection{Nguyên liệu}

Theo phương pháp của Skehan \& cs. (1990) [7] và Likhiwitayawuid \& cs. (1993) [8] đã được áp dụng tại Viện nghiên cứu ung thư Quốc gia của Mỹ (NCI) và trường đại học Dược, đại học Tổng hợp Illinois, Chicago, Mỹ.

\section{Dòng tế bào:}

Dòng Hep-G2 (Human hepatocellular carcinoma - Ung thu gan)

Dòng Lu-1 (Human lung adenocarcinoma Ung thư biểu mô phổi)

Dòng MCF-7 (Human breast adenocarcinoma Ung thư vú)

\section{Môi truò̀ng và các dụng cụ, hóa chất:}

Môi trường DMEM (Dulbecco's Modified Eagle Medium) hoặc MEME (Minimum Essential Medium with Eagle's salt) có bổ sung LGlutamine, Sodium piruvat, $\mathrm{NaHCO}_{3}, \quad$ PSF (Penicillin - Streptomycin sulfate - Fungizone); NAA (Non-Essential Amino Acids); 10\% BCS (Bovine Calf Serum), Tripsin-EDTA 0,05\%; DMSO (Dimethyl Sulfoside); TCA (Trichloro Acetic acid); Tris Base; PBS (Phosphate Buffered Saline); SRB (Sulfo Rhodamine B); Acid acetic.

Các dụng cụ dùng 1 lần: Bình nuôi cấy tế bào, phiến vi lượng 96 giếng, pipet pasteur, các đầu týp cho micropipet...

Chất chuẩn chứng dưong tính: Ellipticine pha trong DMSO.

\subsection{Phuơng pháp tiến hành}

Phép thử tiến hành xác định hàm lượng protein tế bào tổng số dựa vào mật độ quang học (OD Optical Density) đo được khi thành phần protein của tế bào được nhuộm bằng Sulforhodamine $\mathrm{B}$ (SRB). Giá trị OD máy đo được tỉ lệ thuận với 
lượng SRB gắn với phân tử protein, do đó lượng tế bào càng nhiều (lượng protein càng nhiều) thì giá trị $\mathrm{OD}$ càng lớn. Phép thử được thực hiện trong điều kiện cụ thể như sau: Chất thử $(10 \mu \mathrm{l})$ pha trong DMSO 10\% được đưa vào các giếng của khay 96 giếng để có nồng độ sàng lọc là $100 \mu \mathrm{g} / \mathrm{ml}$. Chất thử có hoạt tính được xác định $\mathrm{IC}_{50}$ nhờ dải nồng độ $100 \mu \mathrm{g} / \mathrm{ml} ; 20 \mu \mathrm{g} / \mathrm{ml} ; 4 \mu \mathrm{g} / \mathrm{ml} ; 0,8 \mu \mathrm{g} / \mathrm{ml}$. Trypsin hóa tế bào thí nghiệm để làm rời tế bào và đếm trong buồng đếm để điều chỉnh mật độ cho phù hợp với thí nghiệm. Thêm vào các giếng thí nghiệm lượng tế bào phù hợp (trong $190 \mu \mathrm{l}$ môi trường) và để chúng phát triển trong vòng từ 3-5 ngày. Một khay 96 giếng khác không có chất thử nhưng có tế bào ung thư $(190 \mu \mathrm{l})$ sẽ được sử dụng làm đối chứng ngày 0 . Sau 1 giờ, đĩa đối chứng ngày 0 sẽ được cố định tế bào bằng Trichloroacetic acid TCA. Sau giai đoạn phát triển trong tủ ấm $\mathrm{CO}_{2}$, tế bào được cố định vào đáy giếng bằng TCA trong 30 phút, được nhuộm bằng $\mathrm{SRB}$ trong 1 giờ ở $37{ }^{\circ} \mathrm{C}$. Đổ bỏ $\mathrm{SRB}$ và các giếng thí nghiệm được rửa 3 lần bằng $5 \%$ acetic acid rồi để khô trong không khí ở nhiệt độ phòng. Cuối cùng, sử dụng $10 \mu \mathrm{M}$ dung dịch base Tris để hòa tan lượng SRB đã bám và nhuộm các phân tử protein, đưa lên máy lắc đĩa lắc nhẹ trong 10 phút và sử dụng máy ELISA Plate Reader (Bio-Rad) để đọc kết quả về hàm lượng màu của chất nhuộm SRB qua phổ hấp phụ ở bước sóng $515 \mathrm{~nm}$. Các phép thử được lặp lại 3 lần để đảm bảo tính chính xác. Ellipticine (Sigma) luôn được sử dụng như là chất đối chứng dương và được thử nghiệm ở các nồng độ: $10 \mu \mathrm{g} / \mathrm{ml}, 2 \mu \mathrm{g} / \mathrm{ml}, 0,4$ $\mu \mathrm{g} / \mathrm{ml}$ và $0,08 \mu \mathrm{g} / \mathrm{ml}$. DMSO $10 \%$ luôn được sử dụng như đối chứng âm.

\subsection{Tính kết quả}

Kết quả được đọc trên máy ELISA ở bước sóng 495-515 nm.

Giá trị CS (Cell Survival): là khả năng sống sót của tế bào ở nồng độ nào đó của chất thử tính theo \% so với đối chứng. Dựa trên kết quả đo được của chứng $\mathrm{OD}$ (ngày 0 ), DMSO $10 \%$ và so sánh với giá trị $\mathrm{OD}$ khi trộn mẫu để tìm giá trị CS $(\%)$ theo công thức:

$$
C S \%=\frac{\mathrm{OD}(\text { mẫu })-\mathrm{OD}(\text { ngày } 0)}{\mathrm{OD}(\mathrm{DMSO})-\mathrm{OD}(\text { ngày } 0)} \times 100
$$

Giá trị CS (\%) sau khi tính theo công thức trên, đựơc đưa vào tính toán Excel để tìm ra \% trung bình \pm độ lệch tiêu chuẩn của phép thử được lặp lại 3 lần theo công thức của Ducan như sau: Độ lệch tiêu chuẩn $\sigma: \sigma=\sqrt{\left(\sum(x i-\bar{x})^{\wedge} 2\right) /(n-1)}$

Các thử nghiệm được thực hiện tại Viện Hóa học các Hợp chất thiên nhiên, Viện Hàn lâm Khoa học và Công nghệ Việt Nam.

\section{Kết quả nghiên cứu}

\subsection{Thu nhận các cặn chiết}

Lá cây Tử châu lá to: Mẫu sấy khô ở nhiệt độ 60 ${ }^{\circ} \mathrm{C}$ đến khối lượng không đổi được $3500 \mathrm{~g}$, đem nghiền nhỏ và ngâm chiết 5 lần với $\mathrm{MeOH}$ trong thiết bị siêu âm ở nhiệt độ phòng. Dịch tổng thu được cất kiệt dung môi dưới áp suất giảm, nhiệt độ $<50{ }^{\circ} \mathrm{C}$ thu được cặn cô $\mathrm{MeOH}$ (L.CM, 195g). Cặn cô $\mathrm{MeOH}$ được thêm nước và chiết lần lượt với các dung môi có độ phân cực tăng dần $n$-hexane, EtOAc sau đó cất kiệt dung môi thu được các cặn tương ứng: $n$-hexane (CMH: $45 \mathrm{~g}$ ), ethyl acetate (CME: $25 \mathrm{~g}$ ) và nước (CMW: $110 \mathrm{~g}$ ).

Thân cành cây Tử châu lá to: được sấy khô, xay nhỏ thu được bột mẫu khô $(4,5 \mathrm{~kg})$. Bột mẫu khô được ngâm chiết với etanol. Quá trình chiết được thực hiện gián đoạn ở nhiệt độ $40^{\circ} \mathrm{C}$ trong thiết bị chiết siêu âm gia nhiệt 4 lần, mỗi lần khoảng 4-5 giờ. Dịch chiết được gom lại, lọc qua giấy lọc và cất loại dung môi dưới áp suất giảm thu được cặn chiết tổng của thân cành cây Tử châu lá to (T.CM, $230 \mathrm{~g}$ ).

Quả cây Tử châu lá to: được sấy khô, xay nhỏ thu được bột mẫu khô $(0,12 \mathrm{~kg})$. Bột mẫu khô được ngâm chiết với etanol. Quá trình chiết được thực hiện gián đoạn ở nhiệt độ $40^{\circ} \mathrm{C}$ trong thiết bị chiết siêu âm gia nhiệt 4 lần, mỗi lần khoảng 4-5 giờ. Dịch chiết được gom lại, lọc qua giấy lọc và cất loại dung môi dưới áp suất giảm thu được cặn chiết tổng của quả cây Tử châu lá to (Q.CM, $9 \mathrm{~g})$.

Kết quả xử lý và chiết các mẫu thực vật, tạo các cặn chiết tổng và các cặn dịch chiết phân đoạn $n$ hexan, etyl axetat và metanol của cây Tử châu lá to (Callicarpa macrophylla Vahl) được tóm tắt như bảng 1: 
Bảng 1 . Kết quả xử lý và chiết các mẫu Tử châu lá to (Callicarpa macrophylla Vahl)

\begin{tabular}{|c|c|c|c|c|c|c|c|}
\hline \multicolumn{4}{|c|}{ Danh sách mẫu thu thập } & \multicolumn{2}{l|}{ Khối lượng phân đoạn (g) } \\
\hline \multirow{3}{*}{ Ký hiệu mẫu } & $\begin{array}{c}\text { Bộ phận } \\
\text { mẫu }\end{array}$ & $\begin{array}{c}\text { Khối } \\
\text { lượng tươi } \\
(\mathrm{kg})\end{array}$ & $\begin{array}{c}\text { Khối } \\
\text { lượng khô } \\
(\mathrm{kg})\end{array}$ & $\begin{array}{c}\text { Khối } \\
\text { lượng cặn } \\
\text { tổng }(\mathrm{g})\end{array}$ & Hexan & EtOAc & EtOH \\
\hline \multirow{3}{*}{ C. macrophylla } & Lá & 15 & 3,5 & 190 & 45 & 25 & 110 \\
\cline { 2 - 9 } & Quả & 0,5 & 0,12 & 19 & & & \\
\cline { 2 - 10 } & Thân cành & 25 & 4,5 & 230 & & & \\
\hline
\end{tabular}

\section{2. Đánh giá hoạt tính gây độc tế bào in vitro của cao chiết tù̀ loài Tử châu lá to}

Hoạt tính gây độc tế bào in vitro của cặn chiết methanol từ lá, quả và thân cành của cây Tử châu lá to (C. macrophylla) được thử nghiệm trên 3 dòng tế bào ung thư (Lu-1, Hep-G2 và MCF-7) theo phương pháp SRB. Tiếp đó, các dòng tế bào ung thư bị ức chế mạnh nhất bởi cặn chiết methanol sẽ được lựa chọn để sàng lọc hoạt tính của các cặn chiết phân đoạn $n$-hexane, EtOAc và nước. Các mẫu được đánh giá hoạt tính gây độc tế bào trên ba dòng tế bào ung thư. Kết quả thể hiện trong bảng 2 .

Bảng 2. Hoạt tính gây độc tế bào in vitro của các cặn chiết cây Tử châu lá to

\begin{tabular}{|c|c|c|c|c|c|}
\hline \multirow{2}{*}{ TT } & \multirow{2}{*}{ Ký hiệu mẫu } & \multirow{2}{*}{$\begin{array}{c}\text { Nồng độ đầu } \\
\end{array}$} & & \multicolumn{3}{|c|}{ Giá trị CS (\%) của 3 dòng tế bào } \\
\cline { 4 - 6 } & & & Hep-G2 & LU-1 & MCF-7 \\
\hline & DMSO & - & 100 & 100 & 100 \\
\hline & Chứng (+) & 5 & $\mathbf{1 , 3 4} \pm \mathbf{0 , 8}$ & $\mathbf{2 , 6 6} \pm \mathbf{0 , 9}$ & $\mathbf{1 , 2 1} \pm \mathbf{0 , 7}$ \\
\hline $\mathbf{1}$ & $\mathbf{Q . C M}$ & 40 & $60,02 \pm 2,3$ & $47,31 \pm 1,5$ & $38,86 \pm 2,3$ \\
\hline $\mathbf{2}$ & T.CM & 40 & $64,66 \pm 2,2$ & $55,64 \pm 2,8$ & $90,22 \pm 0,2$ \\
\hline $\mathbf{3}$ & L.CM & 40 & $\mathbf{4 7 , 8 4} \pm \mathbf{2 , 1}$ & $\mathbf{3 9 , 4 0} \pm \mathbf{2 , 2}$ & $\mathbf{3 0 , 2 3} \pm \mathbf{1 , 5}$ \\
\hline
\end{tabular}

Kết quả cho thấy cặn chiết tổng methanol (ethnanol) từ lá, quả, thân loài Tử châu lá to thể hiện hoạt tính ức chế tốt trên 3 dòng tế bào ung thư thử nghiệm với các giá trị $\mathrm{CS}(\%)$ trong khoảng từ $30,23 \pm 1,5$ đến $90,22 \pm 0,15 \%$. Đặc biệt cặn chiết methanol của lá cây Tử châu lá to (L.CM) có tác dụng ức chế tốt với giá trị CS (\%) là 47,84 $\pm 2,1$ (đối với dòng tế bào ung thư Hep-G2); 39,40 $\pm 2,2$ (đối với dòng tế bào ung thư Lu-1) và 30,23 $\pm 1,5$ (đối với dòng tế bào ung thư MCF-7).

Qua kết quả sàng lọc sơ bộ hoạt tính gây độc tế bào ung thư đối với 03 dòng tế bào ung thư HepG2, Lu-1 và MCF-7 cho thấy lá cây Tử châu lá to có tác dụng mạnh hơn quả và thân cành của chúng. Do vậy, các nghiên cứu về hoạt tính và thành phần hóa học tiếp theo ưu tiên tập trung vào lá cây Tử châu lá to.

Tiếp tục thử hoạt tính của các cặn chiết phân đoạn $n$-hexane, EtOAc và methanol của lá cây Tử châu lá to đối với dòng tế bào ung thư Hep-G2, Lu1 và MCF-7, kết quả thử nghiệm được thể hiện ở bảng 3. Ngoại trừ cặn chiết phân đoạn methanol hầu như không thể hiện hoạt tính, cả 2 cặn chiết phân đoạn còn lại của lá loài này đều có tác dụng ở các mức độ khác nhau, trong đó phân đoạn $n$ hexane (L.CM.H) thể hiện hoạt tính mạnh nhất với các giá trị CS (\%) thấp với giá trị CS (\%) từ 12,49 $\pm 1,4$ đến $20,18 \pm 0,8 \%$. Kết quả này được giải thích là do sự hiện diện của các nhóm chất có hoạt tính gây độc tế bào mạnh như terpenoid và flavonoid trong các phân đoạn có độ phân cực yếu và trung bình. 
Bảng 3. Hoạt tính gây độc tế bào của các cặn chiết phân đoạn từ lá cây Tử châu lá to

\begin{tabular}{|c|c|c|c|c|c|}
\hline \multirow{2}{*}{ TT } & \multirow{2}{*}{ Ký hiệu mẫu } & \multirow{2}{*}{$\begin{array}{c}\text { Nồng độ đầu } \\
(\mu \mathrm{g} / \mathrm{ml})\end{array}$} & \multicolumn{3}{|c|}{ Giá trị CS (\%) của 3 dòng tế bào } \\
\cline { 4 - 6 } & & & Hep-G2 & LU-1 & MCF-7 \\
\hline & DMSO & - & 100 & 100 & 100 \\
\hline & Chứng $(+)$ & 5 & $\mathbf{1 , 3 4} \pm \mathbf{0 , 8}$ & $\mathbf{2 , 6 6} \pm \mathbf{0 , 9}$ & $\mathbf{1 , 2 1} \pm \mathbf{0 , 7 1}$ \\
\hline $\mathbf{1}$ & L.CM.H & 40 & $\mathbf{2 0 , 1 8} \pm \mathbf{0 , 8}$ & $\mathbf{1 2 , 4 9} \pm \mathbf{1 , 4}$ & $\mathbf{1 1 , 6 1} \pm \mathbf{2 , 1 1}$ \\
\hline $\mathbf{2}$ & L.CM.E & 40 & $98,03 \pm 0,9$ & $\mathbf{1 8 , 2 0} \pm \mathbf{1 , 3}$ & $\mathbf{4 0 , 4 3} \pm \mathbf{2 , 7 9}$ \\
\hline $\mathbf{3}$ & L.CM.M & 40 & 100 & 100 & $91,29 \pm 0,32$ \\
\hline
\end{tabular}

(L: lá, H: n-hexane, E: ethyl acetate, M: methanol, CM: C. macrophylla)

\section{KẾT LUẬN}

Cặn chiết tổng methanol (ethnanol) từ lá, quả, thân loài Tử châu lá to thể hiện hoạt tính ức chế tốt trên 3 dòng tế bào ung thư thử nghiệm với các giá trị CS (\%) trong khoảng từ 30,23 $\pm 1,5$ đến 90,22 \pm $0,15 \%$. Cặn chiết methanol của lá cây Tử châu lá to (L.CM) có tác dụng ức chế tốt với giá trị CS (\%) từ $30,23 \pm 1,5$ đến $47,84 \pm 2,1 \%$.

Các cặn chiết phân đoạn $n$-hexane, EtOAc và methanol của lá cây Tử châu lá to đối với dòng tế bào ung thư Hep-G2, Lu-1 và MCF-7, ngoại trừ cặn chiết phân đoạn methanol hầu như không thể hiện hoạt tính, cả 2 cặn chiết phân đoạn còn lại của lá loài này đều có tác dụng ở các mức độ khác nhau, trong đó phân đoạn $n$-hexane (L.CM.H) thể hiện hoạt tính mạnh nhất với giá trị CS (\%) từ 12,49 \pm 1,4 đến $20,18 \pm 0,8 \%$.

\section{REFERENCES}

[1] Phuong, V.X. (2007). Science and technics publishing house Flora of Vietnam Verbenaceae. Scientific \& Technical Publishing, Hanoi, 6, 284, Vietnam.

[2] Jones William. P., Kinghorn A.D. (2008). Biologically active natural products of the genus Callicarpa. Current bioactive compounds 4(1): 1532.
[3] Yanhua, T., Lianna, S., Meili, Guo., Wansheng, C. (2013). The medicinal uses of Callicarpa L. in traditional Chinese medicine: An ethnopharmacological, phytochemical and pharmacological review. Journal of ethnopharmacology, 146(2): 465-481.

[4] Chi, V.V. (2012). Dictionary on Vietnamese Medicinal Plants. Publishers of Medical, Ho Chi Minh City, 2, 198, Vietnam.

[5] Ho, P.H. (2000). Vietnamese plants. Tre Publishing House. Ho Chi Minh City, 213-216, Vietnam.

[6] Ban, N.T. (2003). Checklist of Plant Species of Vietnam. Agriculture Publishing House, Hanoi, 2, 284-286, Vietnam.

[7] Skehan, P., Storeng, R., Scudiero, D., Monks, A., $\quad$ McMahon, J., $\quad$ Vistica, D., Warren, J.T., Bokesch, H., Kenney, S., Boyd, M.R. (1990). New Colorimetric Cytotoxicity Assay for Anticancer-Drug Screening. Journal of National Cancer Institute 82(13): 1107-1112.

[8] Likhitwitayawuid, K., Angerhofer, C.K., Cordell, G.A., Pezzuto, J.M., Ruangrungsi, N. (1993). Cytotoxic and antimalarial bisbenzylisoquinoline alkaloids from Stephania erecta. Journal of Natural Products. 56(1): 30-38. 